\title{
Esthetic Treatment for Children with Molar Incisor Hypomineralization: A Change in Quality of Life
}

\author{
Mónica Rodríguez Rodríguez* \\ Orthodontic and Pediatric Dentistry Department, Universidad Central de Venezuela, Caracas, Venezuela, South America
}

*Corresponding author: Mónica Rodríguez Rodríguez, Orthodontic and Pediatric Dentistry Department, Universidad Central de Venezuela, Caracas, Venezuela, South America.
Received Date: July 22, 2021

Published Date: August 04, 2021

\section{Mini Review}

Molar Incisor Hypomineralization (MIH) is defined as a qualitative enamel defect, characterized by an alteration in dental structure in one to four of the first permanent molars, with or without involvement of permanent incisors. Demarcated opacities, posteruptive breakdowns, atypical dental caries and atypical restoration are considered diagnose criteria [1-3]. The global prevalence of MIH has been estimated between $11.24 \%$ and $14.2 \%$; despite the wide variability in global epidemiological data $[4,5]$. Prenatal, perinatal and early life illnesses or events have been studied as causative or contributing factors; the clinical presentation suggests a multifactorial origin related to disruption in the amelogenesis process [2, 3].

In most cases, permanent incisors are less affected than first permanent molars. Patients with incisor involvement usually have aesthetics complaints, avoiding smiling and self-confidence problems. These co-morbidities produce additional complications in dental treatment, especially in young patients with immature anterior teeth and extensive pulp tissue $[2,6]$.

Some clinicians consider that MIH opacities in anterior teeth often improve in long term and prefer to postpone aesthetic treatment until permanent dentition stage [7]. Nevertheless, young patients with aesthetic complaints require appropriate and timely dental treatment. In these cases, a conservative approach is the best alternative [2]. Remineralization, microabrasion, dental vital bleaching, resin infiltration and composite restorations have been considered adequate interventions for children with MIH incisors.

In 2016, three studies related to treatment in incisor were included in a systematic review on managing MIH, two different strategies were evaluated: microabrasion and composite resin veneers. Authors concluded that it was no possible to give clear recommendations for MIH-incisors. Also, in the review was mentioned, that incisor remineralization with casein phosphopeptide amorphous calcium phosphate was tested and produced improvement in the enamel morphology [8]. Restrepo, et al. [9] found no favorable effect on remineralization of $\mathrm{MIH}$ incisors after four applications of $5 \% \mathrm{NaF}$ varnish with one-week interval, compared to usual home-care, in opacities measured by Quantitative Light-Induced Fluorescence [9].

Microabrasion technique produces a chemical erosion of the superficial layer of the affected enamel, being considered a minimal invasive approach [10]. Microabrasion may produce a reasonable change in white/creamy MIH opacities; a combination of microabrasion and dental vital bleaching may be useful for more profound defects [7].

Dental vital bleaching was considered by Ghanim et al., a reliable treatment in adolescents with MIH-incisors [7]. The American Academy of Pediatric Dentistry have recognized an increased in the desire for improved dental esthetic by children and adolescents, mostly related to tooth discolorations. The negative impact of dental condition on adolescent's self-image could be considered an indication for tooth whitening [11]. A survey based study was published in 2019, evaluating EAPD's members practices of vital bleaching for children with dental anomalies. Authors reported that $58 \%$ of respondents, who provided bleaching, used $10 \%$ carbamide peroxide and, also this group of participants tended to consider children's concerns [12]. Generally, complications related to 
gingival alterations, sensitivity and pulpal response are referred by clinicians, as deciding factors in dental vital bleaching for children.

In regard to resin infiltration, Crombie, et al. [13] examined microscopically MIH-lesions to evaluate infiltrant penetration and microhardness, finding that caries infiltrant resin could penetrate MIH-lesions with an unreliable pattern and unpredictable changes in hardness [13]. Later, in 2017, Kumar, et al. [14] published an in vitro study, concluding that resin infiltration did not increase microhardness in enamel hypomineralised lesions; consequently authors did not recommend it as an effective clinical procedure [14]. In contrast, a recent clinical trial conducted in 51 children with MIH-diagnose, concluded that resin infiltration produce a positive effect in structural integrity of MIH-teeth, decreasing the risk of posteruptive breakdowns [15].

In practice, clinicians find resin infiltration may produce a positive result in patient and parent's expectation, with concerns related to long terms results. Characteristically, $\mathrm{MIH}$ is an asymmetrical defect; a patient may present teeth with white/ creamy opacities and yellow/brown opacities in others teeth, indeed one single tooth may show a combined colored opacity. These clinical findings have an important impact in treatment results. Resin infiltration is considered an effective treatment for masking white opacities, but it has limited results in yellow/ brownish opacities. Microabrasion and dental bleaching may be combined to improve esthetic results in MIH opacities; proper skills and experience is required in combined approaches, considering possible negative response of extensive pulpal tissue in children with mixed and early permanent dentition.

In 2020, Hasmun, et al. [16] published an intervention study; microabrasion, resin infiltration, tooth whitening and composite restoration were performed in anterior teeth (mean of three) of children between 7 and 16 years old, with diagnosis of MIH. $62,1 \%$ of patients were treated with a combined technique of microabrasion and resin infiltration. Participants were followed for a 6-month period. Authors conclude that conservative interventions produced a significant improvement in children's oral health-related quality of life. Also, it was mentioned the positive impact in children's feeling and confidence at school [16].

Definitely, aesthetic concerns may produce negative impact in quality of life and psychosocial development in children with $\mathrm{MIH}$ incisors. Clinicians usually take decisions based in evidence and experience; traditionally main goal is to achieve the best functional, aesthetic and long term results. According to published data, interventions approaches in affected anterior teeth seemed to have limited outcomes for clinician's expectations. Patient and parents need to be aware of possible results of proposed treatments to avoid postoperative discomfort. Interestingly, these treatments do produce a significant change in children lives. Humanized dentistry philosophy seems to play an important role in clinical decisions for customized therapy in children with MIH.

\section{Acknowledgment}

None.

\section{Conflict of Interest}

No conflict of interest.

\section{References}

1. Ghanim A, Mariño R, Manton D (2019) Validity and reproducibility testing of the Molar Incisor Hypomineralisation (MIH) Index. Int J Paediatr Dent 29: 6-13.

2. Almuallem Z, Busuttil Naudi A (2018) Molar incisor hypomineralisation (MIH)-an overview. Br Dent J.

3. Silva MJ, Scurrah KJ, Craig JM, Manton DJ, Kilpatrick N (2016) Etiology of molar incisor hypomineralization-A systematic review. Community Dent Oral Epidemiol 44: 342-353.

4. Pentapati KC, Yeturu SK, Siddiq H (2017) Systematic review and metaanalysis of the prevalence of molar-incisor hypomineralization. J Int Oral Health 9: 243-250

5. Zhao D, Dong B, Yu D, Ren Q Sun Y (2018) The prevalence of molar incisor hypomineralization: evidence from 70 studies. Int J Paediatr Dent 28: 170-179.

6. Mastroberardino S, Campus G, Strohmenger I, Villa A, Cagetti MG (2012) An Innovative Approach to Treat Incisors Hypomineralization (MIH): A Combined Use of Casein Phosphopeptide-Amorphous Calcium Phosphate and Hydrogen Peroxide-A Case Report. Case Rep Dent : 379593.

7. Ghanim A, Silva MJ, Elfrink MEC, Lygidakis NA, Mariño RJ, et al. (2017) Molar incisor hypomineralisation (MIH) training manual for clinical field surveys and practice. Eur Arch Paediatr Dent 18: 225-242.

8. Elhennawy K, Schwendike F (2016) Managing molar incisor hypomineralization: A Systematic Review. J Dent 55: 16-24.

9. Restrepo M, Jeremias F, Santos Pinto L, Cordeiro RC, Zuanon AC (2016) Effect of Fluoride Varnish on Enamel Remineralization in Anterior Teeth with Molar Incisor Hypomineralization. J Clin Peadiatr Dent 40 207-210.

10. Da Cunha Coelho ASE, Mata PCM, Lino CA, Macho VMP, Areias CMFGP, et al. (2019) Dental hypomineralization treatment: A systematic review. J Esthet Restor Dent 31: 26-39.

11. American Academy of Pediatric Dentistry 2020. Policy on the use of dental bleaching for child and adolescent patients. The Reference Manual of Pediatric Dentistry. Chicago, Ill: American Academy of Pediatric Dentistry: 112-115.

12. Monteiro J, Ashley PF, Parekh S (2020) Vital bleaching for children with dental anomalies: EAPD members' survey. Eur Arch Paediatr Dent 21: 565-571.

13. Crombie F, Manton D, Palamara J, Reynolds E (2014) Resin infiltration of developmentally hypomineralised enamel. Int J Paediatr Dent 24: 51-55.

14. Kumar H, Palamara JEA, Burrow MF, Manton DJ (2017) An investigation into the effect of a resin infiltrant on the micromechanical properties of hypomineralised enamel. Int J Paediatr Dent 27: 399-411.

15. Nogueira VKC, Mendes Soares IP, Fragelli CMB, Boldieri T, Manton DJ, et al. (2021) Structural integrity of MIH-affected teeth after treatment with fluoride varnish or resin infiltration: An 18-Month randomized clinical trial. J Dent 105: 103570

16. Hasmun N, Vettore MV, Lawson JA, Elcock C, Zaitoun H, et al. (2020) Determinants of children's oral health-related quality of life following aesthetic treatment of enamel opacities. Journal of Dentistry 98: 103372. 